\title{
REVIEW
}

\section{Multivariate Curve Resolution Alternating Least Squares Applied to Chromatographic Data: From the Basics to the Recent Advances}

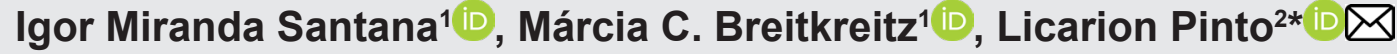

${ }^{1}$ Departamento de Química Analítica, Instituto de Química, Universidade Estadual de Campinas (UNICAMP), Rua Josué de Castro, s/n, 13083-970, Campinas, São Paulo, Brazil

${ }^{2}$ Departamento de Química Fundamental, Universidade Federal de Pernambuco (UFPE), Av. Jornalista Anibal Fernandes, s/nº - Cidade Universitária, 50740-540, Recife, Pernambuco, Brazil

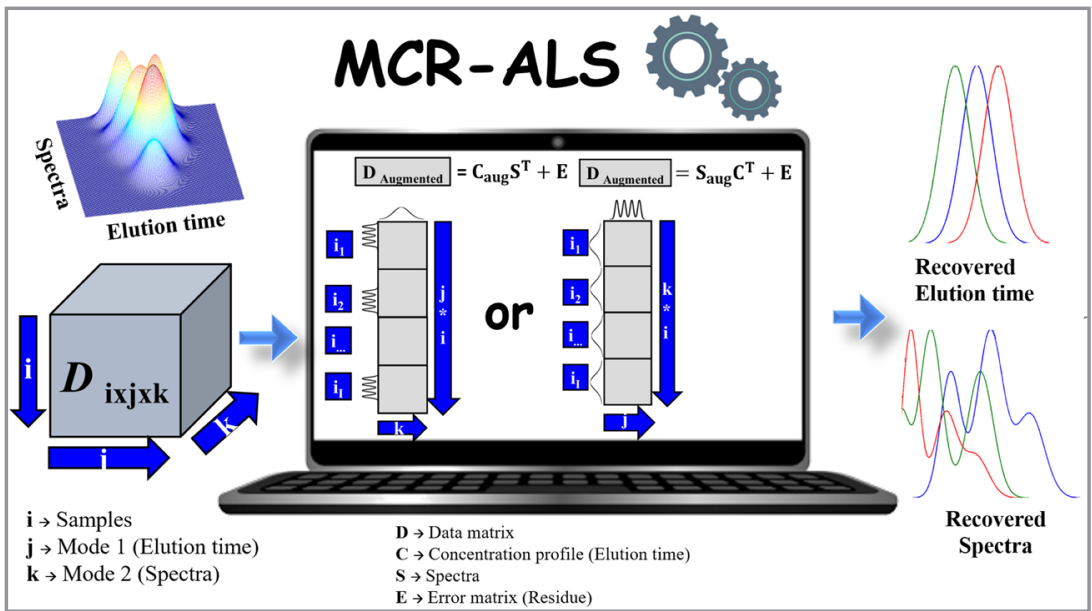

This revision presents applications of multivariate curve resolution alternating least squares (MCR-ALS) applied to chromatographic data. Initially, the fundamentals and recent advances of the MCR-ALS method will be presented. Several critical issues such as data organization, advantages of the modelling, constraints, evaluation of ambiguity and the use for mathematical separation is discussed. An extensive revision of the papers on MCR-ALS applied to chromatographic data reported up to 2020 is presented.

A practical example of an innovative application of cholesterol lowering drugs using supercritical fluid chromatography (SFC) is described highlighting important aspects of the method. At the end, a list of links to MCR-ALS algorithms and graphical interfaces developed in Matlab, R and Python 3 is provided.

Keywords: Multivariate curve resolution, Chromatography, statins, multiway, mathematical separation.

\section{INTRODUCTION}

Over the last decade the number of published manuscripts describing the use of multivariate curve resolution with alternating least squares (MCR-ALS) for chromatographic data analysis has increased, especially after the first time the word "chroMATHography" was used to refer to the mathematical separation that can be achieved using curve resolution methods [1-3].

Cite: Santana, I. M.; Breitkreitz, M. C.; Pinto, L. Multivariate Curve Resolution Alternating Least Squares Applied to Chromatographic Data: From the Basics to the Recent Advances. Braz. J. Anal. Chem., 2021, 8 (32), pp 22-44. doi: http://dx.doi. org/10.30744/brjac.2179-3425.RV-30-2021

Submitted 01 March 2021, Resubmitted 14 June 2021, $2^{\text {nd }}$ time Resubmitted 25 June 2021, Accepted 25 June 2021 , Available online 21 July 2021. 
Since the first paper of curve resolution analysis was published in 1971 [4] and the first work of multivariate curve resolution [5] was published in 1984, the chromatographic instrumentation evolved to make it easier and faster the acquisition of high amount of spectral data synchronized to the chromatographic elution. Multiway data, which encompasses second or higher order data can be obtained in several different ways by synchronizing two or more acquisition modes [6]: Excitation emission 3D molecular fluorescence [7-10], kinetic process followed by an ultraviolet or molecular fluorescence detector [11-14], to name a few. The automated chromatographic instrumentation simplifies the synchronization with a spectrometer detector which makes the process of acquiring higher order data easier. For example, liquid chromatography coupled to photodiode array detector (LC-PDA) [3,6,15-18], liquid chromatography coupled to fluorescence detector (LC-FLU) [17,19-23], liquid or gas chromatography coupled to mass spectrometer (LC-MS or GC-MS) [17,24-29], multidimensional liquid or gas chromatography (MDLC or MDGC) [17,26-28,30-33] and kinetic process followed by a chromatographic analysis [34] are some of the numerous way to obtain higher order data using a chromatographic system.

When the signal of one or more analytes are mathematically unmixed from interferents using a curve resolution method, pure profiles of these analytes are obtained [1], which can be used for many purposes such as calibration $[3,6,15-17,20,23]$, pattern recognition $[24,25,30]$ or even to evaluate the purity of the peak $[34,35]$. This mathematical separation is possible due to the second order advantage $[6,17,20,23,36,37]$ and provides several benefits for the analytical method development: (1) clean-up and sample preparation protocols may be significantly reduced in time and complexity; (2) full chromatographic separation is no longer a requirement to perform an accurate quantification; (3) baseline profile can be retrieved as an extra profile and may be mathematically removed from the modelling; (4) the same elution can be used to analyze different types of samples which facilitates the development of multiproduct analysis; (5) the results of validation regarding the figures of merit can be enhanced by the increase of synchronized detection modes; (6) better accuracy can be achieved even for highly complex samples, (7) it is possible to analyze coeluted samples with identical spectra profile [3,6,15-17,19,20,24,29,30,32,34,37-39].

MCR-ALS is a flexible algorithm that presents several advantages on modelling chromatographic data. Many implemented constraints make the MCR-ALS more adaptable to different systems and can be used to efficiently retrieve pure signals of the mixture constituents. In this context, this paper provides a systematical review of the fundamental and recent publications of MCR-ALS algorithm applied to chromatographic data. Illustrative examples will be used to highlight different applications and advantages of replacing the physical-chemical separation by the mathematical separation. In addition, a new application of MCR-ALS on supercritical fluid chromatography (SFC) is reported.

\section{THEORY OF MULTIWAY ANALYSIS}

This section introduces the nomenclature, data organization, the main problems of chromatographic data for multiway modelling, and the main advantages of multiway modelling with MCR-ALS of chromatographic data.

The instrumental data can be categorized in accordance with the quantity, type and organization of data used for the analysis. In this context, the univariate approach is used when a single result is used to characterize a sample and the multivariate approach when more than one result is used for the same purpose. Univariate modelling does not require much computational effort, so it is frequently implemented in chromatographic systems for identification or quantification. The major disadvantage of this type of modelling is that it requires complete separation of the analyte from the matrix constituents since information from the interferences cannot be taken into account in this approach. This can be time-consuming and might require a large volume of solvents, especially for the analysis of complex samples, and even so an interference may still preclude the analysis. On the other hand, multivariate analysis simplifies laboratory work, however it demands higher computational effort, especially for big data sets and an experienced analyst to evaluate the quality of the model built before its use for predictions. Nevertheless, the ability to identify (first order advantage) and even to make accurate predictions in the presence of interferences 
(second order advantage) make the use of multivariate modelling worthy $[37,38]$. MCR-ALS in the context of chromatographic analysis displays the advantages mentioned for second and higher order data $[6,17,37,38,40,41]$. When there is more than one variable used to build the model the data set is called multivariate, if these variables are acquired with more than one instrument source the multivariate data set can be called multiway. In this sense multivariate is a general concept that includes multiway.

Multiway data is obtained when more than one detection mode is synchronized and the number of these modes are related to the order of the data. Therefore, second order data - also called three-way data - can be built when two acquisition modes are synchronized; third order - also called four-way data - when three modes are synchronized and so on. Figure 1 relates the data to the order; it can be seen that when the sample information is a scalar, vector, matrix or a three-way tensor, the sample dataset are respectively described as zeroth, first, second and third order data [37,38,40].

Second and higher order data present the second order advantage and some authors highlight that the sensitivity is increased with the number of acquisition modes $[6,17,37,38,40]$. The increase in sensitivity is more evident from second to third order data than from third to higher order data, therefore the increase in sensitivity is described as the third order advantage $[37,38]$. Useful information to achieve the second order advantage is obtained when another mode is analyzed [34], however so far, no special advantage was related to the modelling of fourth order data or higher [37].

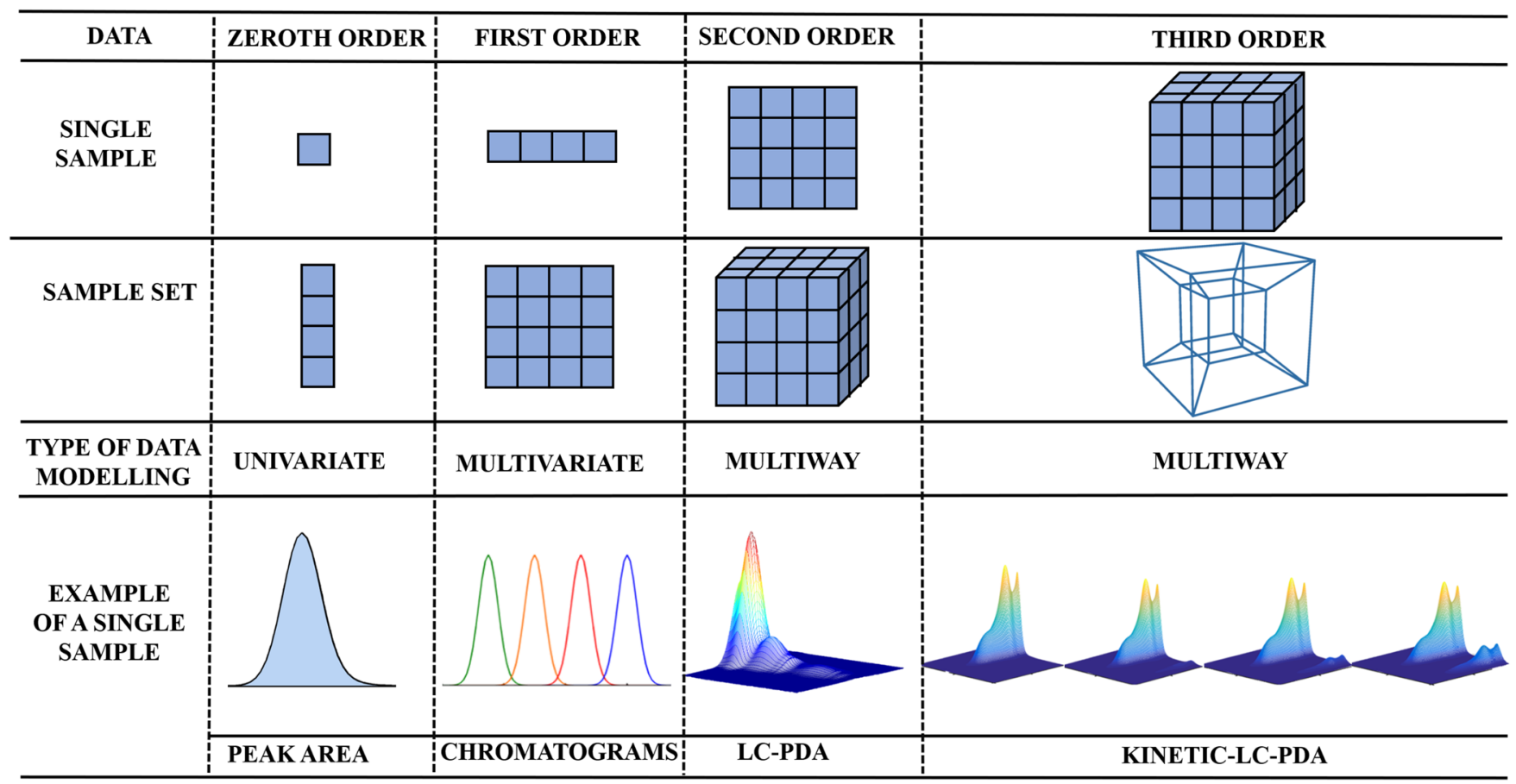

Figure 1. Examples and organization of data type related to data order. [Reprinted (adapted) from Anal. Chim. Acta., 2014, 806, pp 8-26 (https://doi.org/10.1016/j.aca.2013.11.009). Authors: Graciela M. Escandar, Héctor C. Goicoechea, Arsenio Muñoz de la Peña, Alejandro C. Olivieri. Title: Second- and higher-order data generation and calibration: A tutorial. With permission from Elsevier.]

\section{THEORY OF MCR-ALS}

Multivariate curve resolution with alternating least squares is a bilinear algorithm used for curve resolution purposes [1,5,42-45]. It fits particularly well to multiway chromatographic data because each sample is individually bilinear due to the synchronization of the detectors. However, the tensor built with more than one injection is not trilinear or quadrilinear due to retention time shifts and peak shape changes caused by differences in mass transfer process inside the column $[1,6,17,40]$. 
It is important to say that most chemical data sets are bilinear and a few present trilinearity, therefore bilinear algorithms are suitable for most of them. The great disadvantage between bilinear and trilinear models remains in the uniqueness advantage that is achieved only when trilinear models are applied. Several papers describe how to achieve a feasible result with MCR-ALS using different strategies $[1,6,17,40,46]$.

\section{Identifying the number of components: chemical rank analysis}

Before applying MCR-ALS, the number of components present in the system under evaluation should be determined, since the results depend on this parameter, similarly to other curve resolution algorithms. The adequate number of components to start with is ideally equal to the number of chemical constituents of the sample being analyzed. However, instrumental features such as background and noise make this task harder and generally it is necessary to include another profile to explain the baseline especially when gradient is used in a chromatographic elution. There are several ways to estimate the correct chemical rank of a dataset, but principal component analysis (PCA) and single value decomposition (SVD) are the most used for this task [43,47-50]. Other approaches such as morphological score [51] and subspace comparison [52] can be more adequate when the instrumental noise level is high such as for GC-MS data.

It is important to evaluate if there is any breaking mode or rank deficiency due to completely overlapped profiles $[15,34,53,54]$. The easiest way is augmenting the data individually for each acquisition mode, if the number of estimated components differ it is an indicative that there is a breaking mode or a rank deficiency problem. Consider LC-PDA data where there are three chemical compounds without noise or baseline drift. If the data is augmented in the elution mode and the estimated number of components is lower than three this indicates that there are at least two spectra that present strong overlap. On the other side, if the data is augmented in spectral mode and the number of components is lower than three this indicates that there are at least two completely overlapped peaks. In this last situation it is possible to estimate more than three components, and it indicates that there are retention time shifts or peak shape changes between runs, resulting in a trilinear breaking mode. MCR-ALS is capable of dealing with trilinear breaking mode due to retention time shift $[3,16,18,55]$ or strong overlap of profiles $[15,53,54]$ by augmenting the matrix in the mode with this problem, however it is not capable of dealing with both simultaneously without any preprocessing step [15]. In four-way analysis the third acquisition mode can provide information to overcome both problems, as will be discussed in details in the illustrative examples.

\section{MCR-ALS}

MCR-ALS is a bilinear soft modelling algorithm in which the main goal is to resolve a mixture of signals. Since 1971 [4] until now [1] this algorithm has constantly evolved to overcome or at least minimize some limitations. The application of MCR-ALS goes from first-order data to multiway analysis $[3,20,34,43,56,57]$, however the main application field relies on the analysis of chromatographic data [2,41]. In general, MCRALS can be mathematically described by the Equation 1:

$$
\mathbf{D}=\mathbf{C S}^{\top}+\mathbf{E} \quad \text { Equation } 1
$$

where $\mathbf{D}$ is the original data matrix, $\mathbf{C}$ is the augmented matrix (generally retention times), $\mathbf{S}$ is the nonaugmented matrix (generally the spectra) and $\mathbf{E}$ is the residual matrix.

Let us consider a second order data acquired by a system consisting of a Chromatographic coupled to a Detector that registers a spectrum for more than one sample. The original data set is a tensor sized $i \times j \times k$, where $i$ represent the sample, $j$ the elution time and $k$ the ultraviolet spectral dimension modes. Once MCR-ALS is a bilinear algorithm, before modeling, the original sample data must be column-wise augmented. Since there are two acquisition modes, retention times and spectra, the tensor can be columnwise augmented along the retention time $(i j x k)$ or along the spectra for different samples $(i k x j)$. Figure 
2 illustrates this augmentation where each line of the augmented matrix (D) consists of spectra acquired in different retention times for a set of samples (Figure 2a) or the retention times registered in each wavelength for a set of samples (Figure 2b).

Regardless of the configuration, the non-augmented mode must be reproducible between samples and must provide differences between the constituents for feasible resolution of mixture signals and the mode containing overlapped signals should be the augmented one $[1,3,15,20,34,43,53,54]$. Therefore, if the augmented mode is the elution time (a) the spectra of the analyte must not vary between injections and if the elution time presents retention time shift and/or peak shape changes, this will not affect the modeling. On the other side, when the augmented mode is the spectra (b) the retention time should not present retention time shifts or peak shape changes and the signals may be correctly resolved if there are slight differences between retention time even for coeluted constituents (resolution lower than 1.5) with identical spectra [15].

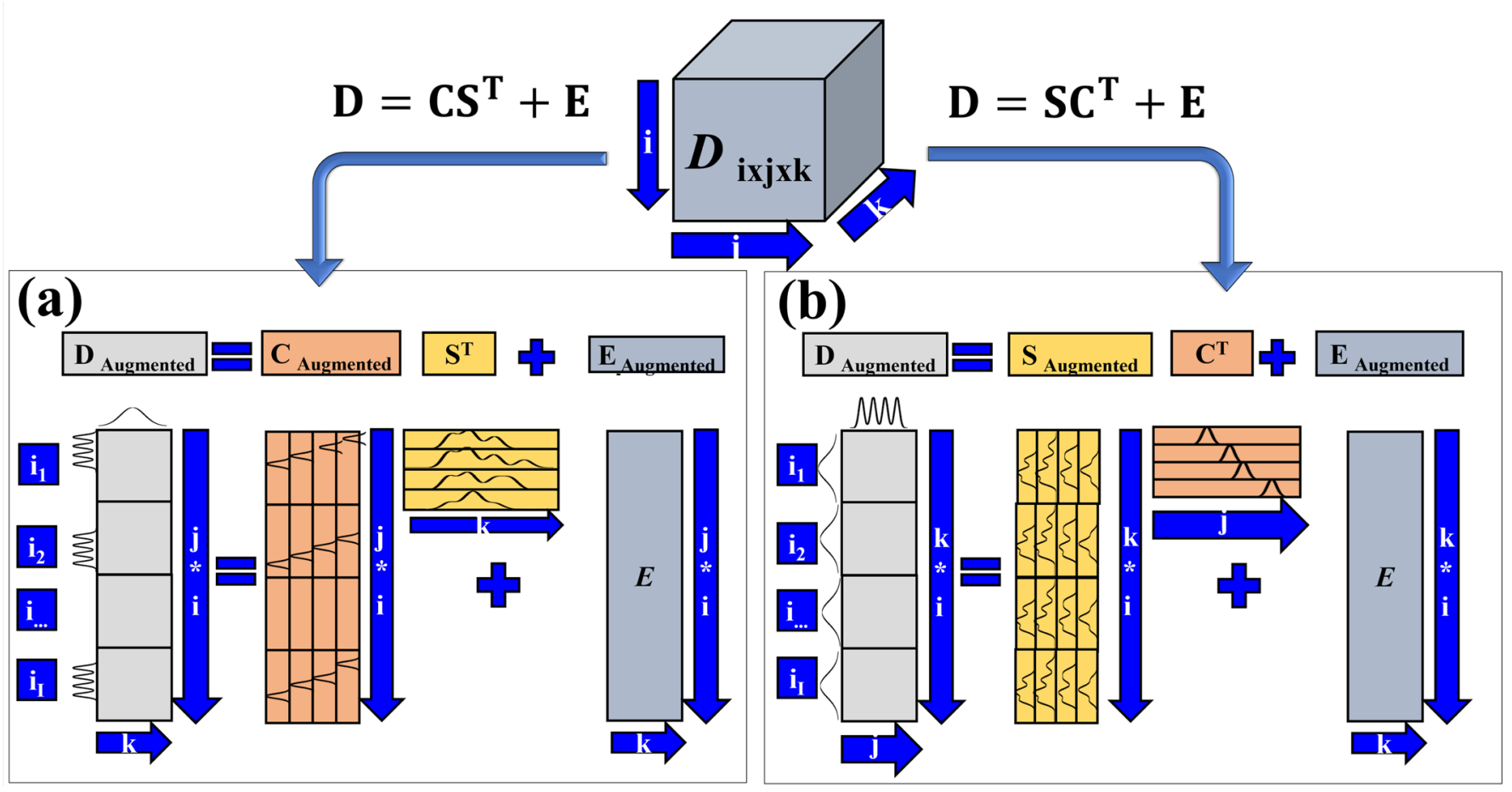

Figure 2. Illustrative scheme of a sample set registered by a chromatographic system coupled with a single detector system augmented in (a) retention time and (b) spectra from a 3D tensor. [Reprinted (adapted) from Anal. Chim. Acta, 2020, 1133, pp 77-87 (https://doi.org/10.1016/j.aca.2020.08.008). Authors: Licarion Pinto, Isabel C.S.F. Jardim, Douglas N. Rutledge, Márcia C. Breitkreitzb. Title: Multiblock modelling on the study of the kinetic degradation of rosuvastatin calcium in the presence of retention time shifts and rank deficiency. With permission from Elsevier.]

The iterative procedure of MCR-ALS algorithm is basically described in the following steps [1,43,59]:

1. Organization of the data in a matrix where the augmented mode is the one that breaks trilinearity or present extreme overlapped profiles;

2. Estimation of the number of constituents that should be resolved;

3. Initial estimate of $\mathbf{C}$ or $\mathbf{S}$;

4. Rebuild of the $\mathbf{D}$ augmented matrix and adjustment of $\mathbf{C}$ and $\mathbf{S}$ with least squares;

5. Repeat step 4 until convergence, which is achieved by the iterative changes of $\mathbf{C}$ and $\mathbf{S}$ matrices until a predefined criterion is established (change between old and new profiles lower than $0.1 \%$ or a previous defined number of iterations). 
After the convergence, the quality criteria of lack of fit (LOF) and explained variance $\left(R^{2}\right)$ is analyzed to evaluate if the rebuilt $\mathbf{D}$ matrix is similar to the original.

The initial estimation is ideally as close as possible to the pure signal of each constituent that MCRALS is trying to retrieve. There are three common approaches to estimate the initial guess of $\mathbf{C}$ and $\mathbf{S}$ : (1) Evolving Factor Analysis, (2) Simple-to-use Interactive Self-modeling Mixture Analysis (SIMPLISMA) or (3) using a known pure spectrum of the target constituent.

The first strategy (EFA) consists of performing a PCA on the elution time adding a new spectrum at a time and it investigates the rise and decay of the components $[60,61]$. In this way, it is possible to identify where each constituent initiates the elution and where it ends; the theory fits well for evolutional data such as chromatography and kinetic data. Therefore, it is not recommended to apply on spectral signals. The second strategy -SIMPLISMA - searches for the purest signals and uses them as the initial estimation. This strategy can be applied in the elution time or in the spectral direction, but it is recommended to apply in the direction where there is a variable with higher purity -which is normally the spectral direction. In cases where the spectra of the constituents are identical, the best direction to search for a pure variable is the elution time $[1,62,63]$. The third strategy to initialize the $\mathrm{C}$ or $\mathrm{S}$ matrix is using the known pure profile, in chromatographic calibration data it is common to have the spectral profile of the analyte and the analyst may use this information to initialize the iterative procedure. However, if the spectra or concentration profiles of all constituents are known and provided as initial estimation, this algorithm turns into a classical least square (CLS) and the step five is not performed. For complex samples generally it is not possible to know all the constituents, therefore in these cases the known spectra are inputted as the initial profile and the other profiles may be better estimated during the ALS procedure. Other approaches of peak purity as Orthogonal Projection Approach (OPA) can be used, but it is not as common as these three above mentioned $[62,64]$.

The high number of applications of MCR-ALS algorithm relies on the flexibility given by the fourth and fifth iterative steps, where the constraints are applied $[1,43,44,46,59]$.

\section{Constraints of MCR-ALS}

The constraints are considered the "art" of MCR-ALS, once they will guide the resolution to a chemically interpretable profile and reduce the ambiguity. Constraints reduce the possible solutions of a bilinear curve resolution decomposition and consequently reduce the ambiguity of the results. There are several constraints that can be used and are implemented in ALS optimization in MCR-ALS GUI interface [43,44]. The most important are: (1) non-negativity, (2) unimodality, (3) multilinearity, (4) correlation, (5) correspondence among components, (6) closure, (7) hard modelling and (8) local rank. Multilinear, correlation, correspondence among components and hard modelling constraints can only be applied to the augmented mode. The other constraints can be applied in both modes.

Other strategies that can be used to reduce the ambiguity are dividing the modelled region to reduce the complexity of the results, which consequently increase the sensitivity [65] and using multiblock analysis.

All the constraints can be applied individually to each individual constituent and may differ among samples. Non-negativity implies that negative values are not acceptable for the mode where it is implemented; this is the most common constraint applied to chemical data. However, it is important to previously analyze the data, it is not possible to apply non-negativity to data that intrinsically present negative values such as circular dichroism [66] or negative baseline profiles [67]. In the first case, non-negativity cannot be used, but in the second case it is possible to retrieve a single profile where non-negativity is not applied to explain the negative baseline or even correct the baseline before MCR-ALS modeling.

Unimodality limits multimodal profiles. It is common to be implemented for elution profiles, where each constituent is expected to present a gaussian shape, i.e., unimodal. Therefore, it is not recommended to implement this constraint to spectra profiles, once they may present more than one maximum for the same constituent. 
Depending on the multilinear constraint [68] implemented, a bilinear model is built for the augmented or super augmented matrix and then an appropriate refolding of each of the augmented profiles is performed using a Kronecker product. Once the model is primordially bilinear, ambiguity may be present in the results, even applying multilinear constraint [46]. However, this constraint implemented in MCR-ALS GUI makes it easier to visualize third order data.

In the correlation constraint, the concentration values calculated for the calibration sample subset are correlated with their known nominal concentration values during ALS optimization by linear regression [69]. The prediction is then performed for the test samples and the scores are displayed as concentration values, skipping additional calculations to predict the analyte concentration.

Correspondence among components $[43,47,48]$ is applied by providing information to the algorithm where the analyte and/or interferents can be retrieved. There are cases, such as calibration with standards, where it is known that the interference is not present in the calibration sample set. Therefore, it is possible to inform the algorithm not to recover the interferent profile on calibration samples because it is known that they are not present there. This constraint is generally applied to calibration samples prepared with standards, once the composition of real samples is not known.

Closure [43] is a constraint that limits the total concentration of the constituents. This constraint follows the mass balance principle and avoids misleading results such as conversion higher than $100 \%$ for a reaction or the initial concentration of the reagents lower than the real concentration. This can be applied by simply limiting the sum of all constituents to a known total concentration.

Hard modelling $[43,70,71]$ is maybe the constraint that has a higher impact to reduce the ambiguity. The resolved profiles are forced to follow a predefined equation. This modeling can be a hybrid of hard and soft modeling by using an equation where the coefficients are adjusted by the ALS optimization process in addition to other constraints. Due to the impact of reducing the number of possible results, the ambiguity is decreased and there is a greater probability of resolving highly overlapped signals.

Local rank, also called equality constraint $[43,47,48,72]$ can be applied when the spectra or concentration profile of the target constituent is known. When standards are used for calibration, it is possible to inform the algorithm of the spectral profile of the analyte that should be resolved. This constraint is different from the initialization with the known spectra, once you may inform only the target profile and the other profiles can be inputted as "not a number" ( $\mathrm{NaN})$. In the case where the spectra are informed with local rank constraint the algorithm is forced to recover that profile, and the $\mathrm{NaN}$ data is free to retrieve the profile that best reduces the residues on ALS optimization. In both cases, the initial profile is previously defined. Remember that $\mathrm{NaN}$ is not allowed as an input for the initial profiles but can be used in equality constraint to receive any number along the iteration process. Therefore, the use of the known spectra is better applied with the strategy of the local rank constraint than at the initialization step.

\section{Data set organization}

In some cases, even the constraints cannot deal with some difficulties that come from the data acquisition or the lack of synchronization between the detection modes. In some situations, these difficulties can generate a non-multilinear data structure $[17,23,34]$. In these situations, the flexibility of MCR-ALS algorithm makes it possible to reorganize the data set in some ways that is possible to achieve correct deconvolution results. For second order data it is possible to use any array organization shown in Figure 2. For third order data it is possible to organize in other ways, such as a super augmented matrix or in a multiset data. 


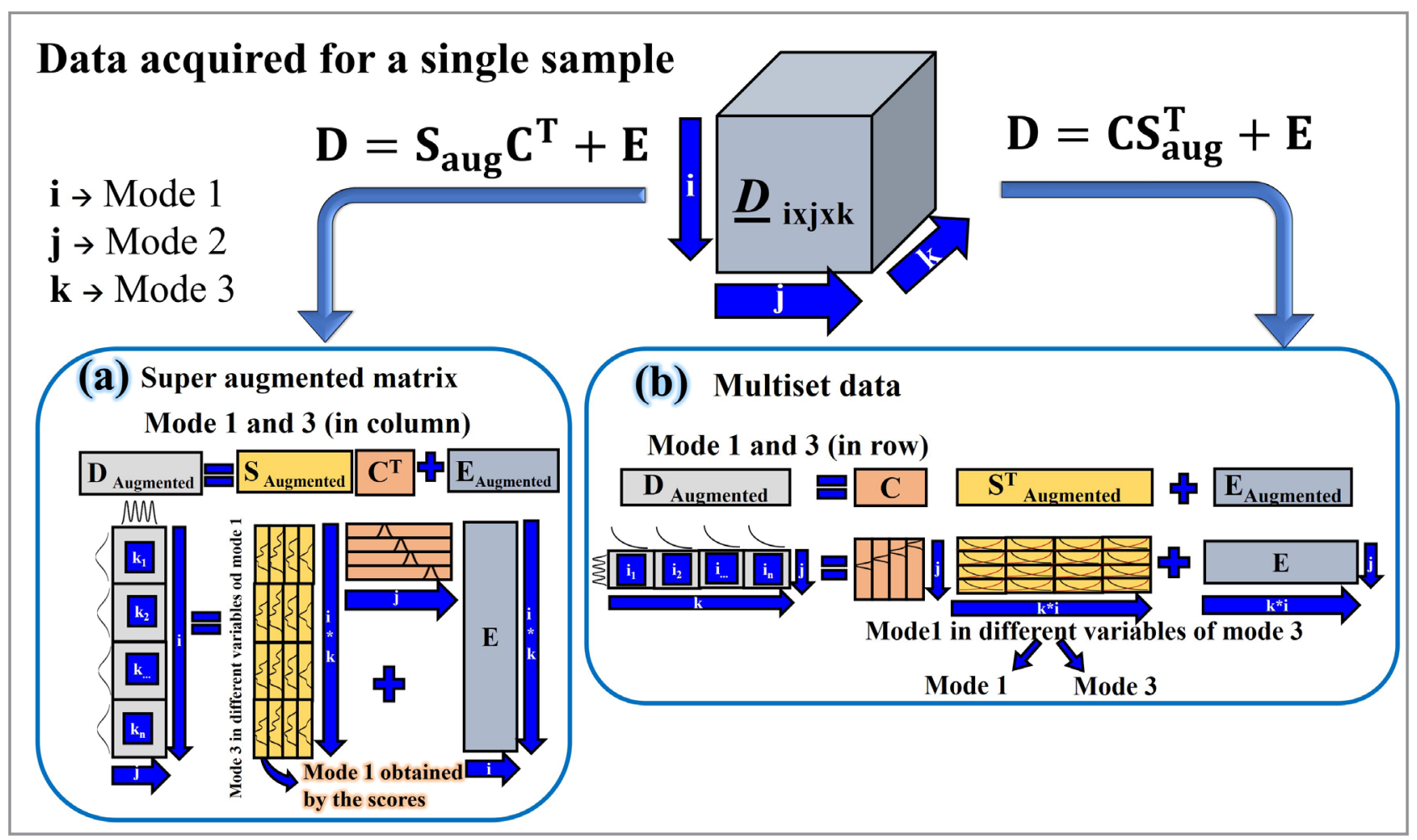

Figure 3. Data organization of a single sample registered by 3 detection modes. Mode 2 is represented as a chromatographic mode, mode 1 and 3 can be other detection modes. The data can be organized in a super augmented matrix (a) or in a Multiset data (b). [Reprinted (adapted) from Anal. Chim. Acta, 2020, 1133, pp 7787 (https://doi.org/10.1016/j.aca.2020.08.008). Authors: Licarion Pinto, Isabel C.S.F. Jardim, Douglas N. Rutledge, Márcia C. Breitkreitzb. Title: Multiblock modelling on the study of the kinetic degradation of rosuvastatin calcium in the presence of retention time shifts and rank deficiency. With permission from Elsevier.]

As discussed before, the MCR-ALS models are based on bilinear data, therefore before modelling a third order data, it must be augmented or unfolded. Figure 3 shows an example where a single sample can be augmented in a super augmented matrix (Figure 3a) and unfolded in a multiset data structure (Figure 3b). A super augmented matrix solves problems in the augmented mode such as dependence between the acquisition modes [17,23] when the non-augmented mode presents differences between the analytes. The multiset data structure is related to a modelling of more than one unfolded detection (non-augmented) mode that must present differences between the analytes in one or both modes. Once in the multiset data structure more than one acquisition mode is used, it is easier for the algorithm to find differences between the analyte and interferences and the results of the deconvolution would be less affected by ambiguity, even if rank deficiency is present in the data set [34].

\section{Ambiguities of MCR-ALS}

Ambiguities are the biggest fragility of MCR-ALS and they can be reduced by applying constraints. The higher the number of constraints, the higher is the reduction of ambiguity. However, it is not possible to affirm that the used constraint will completely eliminate the ambiguity of the bilinear modeling $[44,46,73-82]$.

In MCR-ALS, ambiguity occurs when there is more than one feasible result for $\mathbf{C}$ and $\mathbf{S}$ (Equation 1). Basically, there are three different ambiguities in MCR-ALS: (1) Position Ambiguity, (2) Intensity Ambiguity and (3) Rotational ambiguity. The first one is related to the position of the resolved signal changing between the matrix columns. The second one is related to the differences in intensity between spectra and elution time profiles. Both are easily solved by keeping constant the position of the analyte over the iterations and normalizing the non-augmented profile, respectively. The third one is related to the differences in elution 
and/or recovered spectra profiles and cannot be completely solved, but it can be minimized using the constraints $[43,44,46]$. Figure 4 illustrates these three ambiguities calculated for a simulated LC-PDA data for a sample with a mixture of three constituents.

As can be seen in Figure 4, position and intensity ambiguities do not modify the original shape of the signals, but on the other hand, rotational ambiguity does. By visual comparison of the real and resolved signals, it can be seen that both negative and non-unimodal peaks are possible solutions when no constraint is applied. Besides, a small signal between variables 100 to 150 on resolved spectra is present for the second and third eluted analytes whereas the real profile does not present this signal. Both problems can be solved by applying appropriate constraints.

MCR-BANDS $[44,74]$ solution to calculate the extension of the ambiguities consists of multiplying $\mathbf{C}$ and $\mathbf{S}$ (Equation 1) by an invertible matrix. This can be mathematically expressed by Equation 2 [44], where $\mathbf{T}$ is any invertible matrix, which is:

$$
\widehat{\mathrm{D}}=\mathrm{C}_{\text {old }} \boldsymbol{S}_{\text {old }}^{\mathrm{T}}=\left(\mathrm{C}_{\text {old }} \mathbf{T}^{-1}\right)\left(\mathbf{T S}_{\text {old }}^{\mathrm{T}}\right)=\mathbf{C}_{\text {new }} \mathbf{S}_{\text {new }}^{\mathrm{T}} \quad \text { Equation } 2
$$

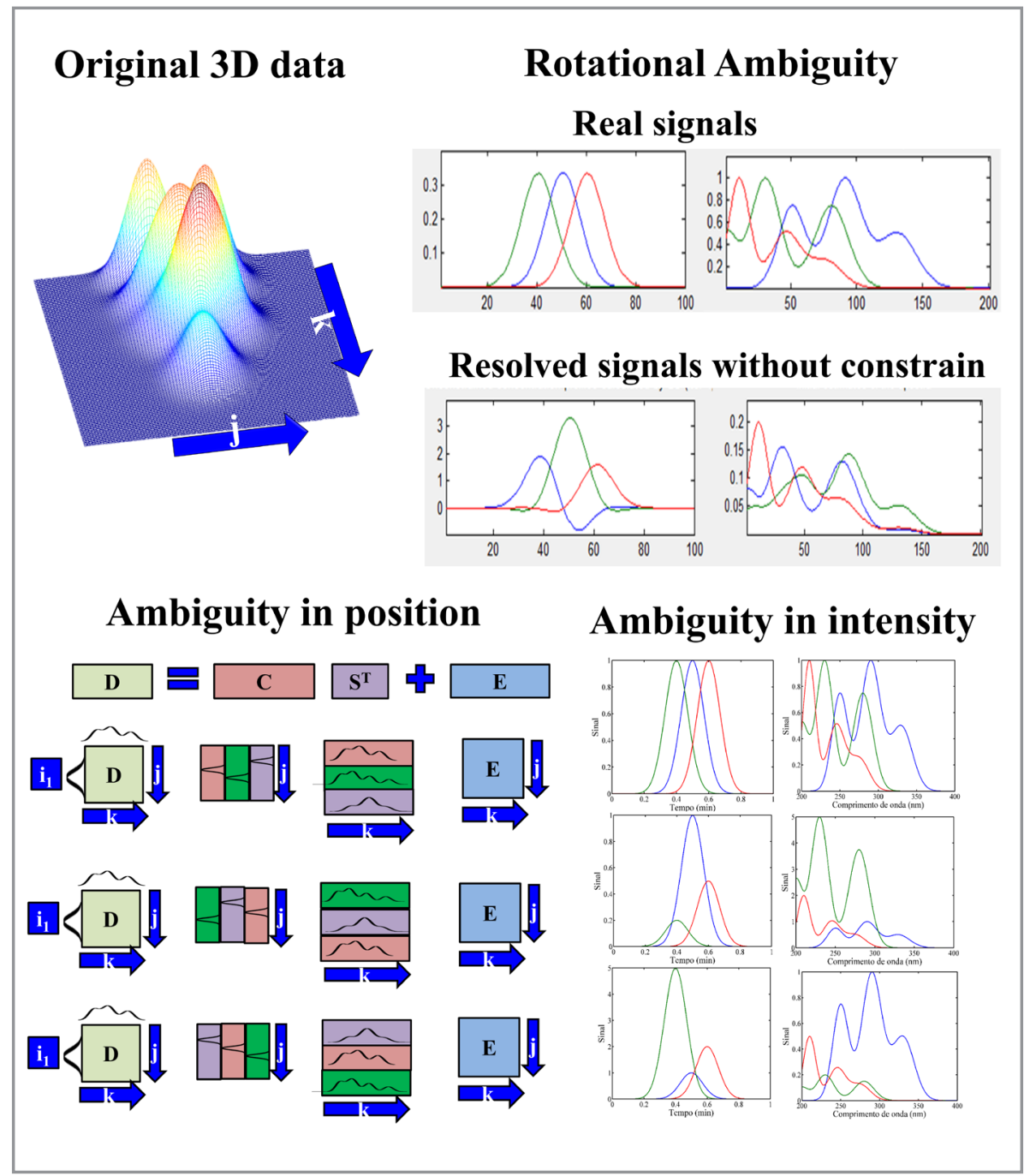

Figure 4. LC-PDA simulated data for a mixture of 3 constituents and examples of position, intensity, and rotational ambiguities. [Reprinted (adapted) from Anal. Chim. Acta., 2014, 806, pp 8-26 (https://doi.org/10.1016/j.aca.2013.11.009). Authors: Graciela M. Escandar, Héctor C. Goicoechea, Arsenio Muñoz de la Peña, Alejandro C. Olivieri. Title: Second- and higher-order data generation and calibration: A tutorial. With permission from Elsevier.] 
The number of possible $T$ matrices is used to calculate the extension of the rotational ambiguity and solutions can be restricted by using constraints. This procedure, implemented in MCR-BANDS, consists in calculating the relative contribution of each constituent to the whole mixture based on the Frobenius norm (f) [44]. The procedure is based on finding $T$ matrices that give maximum (fmax) and minimum (fmin) values of Frobenius norm (relative contribution) for each constituent of the mixture. If the difference between fmax and fmin is near zero, it is said that the rotational ambiguity is low and it is higher as this difference increases.

Recently, a strategy implemented apart from MCR-ALS interfaces can be used to evaluate the extension of the rotational ambiguity using area of feasible solutions (AFS) [73,81-83]. This strategy consists of calculating the feasible solutions for each constituent profile and expressing it as an area. The great disadvantage of this strategy is the limitation of the number of constituents that is possible to simultaneously evaluate, since only 4 constituents can be depicted simultaneously in a three-dimensional space [73,81-83]. A manuscript that compares the evaluation of MCR-BANDS strategy to FACPACK's was published recently [74].

In this paper, the authors try to project the extreme results (fmin and fmax) in the AFS space and it is reported that the values are in the edge of the AFS region. Once with MCR-BANDS strategy it is possible to evaluate the rotational ambiguity for any number of constituents, it is said by the authors that MCRBANDS provides a suitable and simpler solution to evaluate the extension of rotational ambiguity [74].

\section{Figures of merit}

It is necessary to use some metrics to evaluate the quality of a calibration method and to compare it with others. Analytical figures of merits are important metrics used for this purpose. Olivieri used IUPAC's definition of each calibration metric to propose an extension of the well-established univariate figures of merit to first order multivariate and multiway calibration methods [38]. This approach to calculate the multiway figure of merits can be used not only to MCR-ALS but also to other multiway algorithms.

Sensitivity is a crucial parameter to calculate uncertainties and others metrics, and allows the comparison between others methods. Univariate sensitivity is calculated as the slope of the variation of the instrument signal for the change of a concentration unit of the analyte. It is possible to calculate when there is no interference present in the analysis. For first order data the analyte is modelled jointly with other overlapped signals and it is possible to estimate the fraction of the total signal that is related to the analyte, called Net Analyte Signal (NAS). For multiway analysis, where second order advantages are aimed, each sample can present different interference so the contribution of the analyte signal to the sensitivity is calculated by uncertainty propagation $[6,38]$. The equation for the calculation of all figures of merits were detailed by Olivieri at reference [38]. In this reference [38] it was compared multivariate modeling from first to fourth order and it is shown that the sensitivity increases with the order.

From sensitivity it is possible to calculate the limit of detection (LD) and quantification (LQ) using the analytical sensitivity ( $\gamma$, sensitivity divided by error) and the type 1 and type 2 error for 95\% confidence levels. The LD and LQ are respectively calculated as $3.3 \gamma-1$ and $10 \gamma-1$ in terms of concentration level [38]. Some software's implement the figure of merit calculations using graphical interfaces, as will be discussed further on $[47,48]$.

\section{COMMON PREPROCESSING AND CHALLENGES ON MODELING CHROMATOGRAPHIC DATA}

Prior to the use of any multiway algorithm, one needs to know important characteristics of the data to perform adequate modeling, most of them are related to the multi-linearity of the data. In a multiway chromatography data, multi-linearity is the ability to mathematically represent the original multiway data as a linear function of profiles, related to each mode, and the scores that represent the concentration of the target constituent. In this sense, whenever it is possible to represent second order data as a three linear function, this data is called trilinear, while third order data is called quadrilinear, and so on $[23,38]$. 
In the chromatographic field, this implies that both the elution and spectral profiles present the same shape and maximum for a target constituent. This is a reasonable statement for spectra profiles, but not for the elution times. Due to the mass transfer particularities described by the Van Deemter equation, the retention time for an analyte is barely reproducible even for well-adjusted chromatography instruments, especially for samples in which the ionic force varies, runs are longer and large columns are used. Therefore, each sample of second order chromatographic data is bilinear but the set of several samples is not trilinear. The ability of MCR-ALS to deal with trilinearity break fits particularly well the chromatographic data treatment needs, indeed many publications on second and higher order data use this algorithm to deal with retention time shifts and peak shape changes [2,3,6,16,18,19,21,31,33,35]. Even so, there are cases where the alignment before MCR-ALS modeling is required because of rank deficiency $[15,34]$ or to use trilinear-based algorithms [55].

Finally, baseline correction can be used, however is less common than alignment in chromatographic data treatment since, if reproducible, baseline correction can be recovered by curve resolution algorithms as a profile. Derivatives and other preprocessing that changes the profile are preferably avoided because they bring difficulties in analyzing the pure analyte profiles.

\section{LITERATURE EXAMPLES}

MCR-ALS finds fields of application wherever a curve resolution is needed, such as overlapping peaks (see Table I). A search for recent works combining the words "chromatography" and "multivariate curve resolution-alternating least squares" suggests that MCR-ALS is being successfully applied to a myriad of chromatographic problems. Table I shows some selected recent researches with different goals. In general, MCR-ALS was used in chromatographic elution mode (as evidenced by "time-mode augmented" approach) due to the retention time shifts and peak shape changes, resulting in the break of trilinearity, as discussed before. Detection by DAD is preferred because of its simplicity and quantitative ability, but MS is more potent for selective qualitative/fingerprinting studies such as in metabolomics. In addition, fluorescence detection is also employed because of its superior sensitivity and selectivity over DAD, when applicable. One study used surface enhanced Raman spectroscopy (SERS) as detection mode with thin-layer chromatography (TLC), whose overlapping spots where resolved my MCR-ALS. Capillary electrophoresis (CE) with both DAD and MS was also exploited in combination with MCR-ALS. Still, most data involve either GC or HPLC, but recently supercritical fluid chromatography (SFC) was used coupled to DAD for carotenoid analysis in the presence of interferents.

In subsequent paragraphs, the use of MCR-ALS will be exemplified based on five selected papers to describe each data strategy for MCR-ALS application, i.e., time-mode augmented and spectral-mode augmented (non-trilinear data), followed by the modeling of third-order data with non-quadrilinearity problem. Finally, a final section will be dedicated to report a SFC-DAD application from our group. 
Table I. Compilation of papers that used MCR-ALS for chromatographic analysis

\begin{tabular}{|c|c|c|c|c|c|}
\hline $\begin{array}{l}\text { Chromatographic } \\
\text { technique }\end{array}$ & Target compounds & Objective & MCR-ALS approach & $\begin{array}{l}\text { Other chemometrics } \\
\text { techniques used }\end{array}$ & Ref. \\
\hline \multirow{6}{*}{ LC-DAD } & Pesticides in vegetable samples & $\begin{array}{l}\text { Quantitative analysis of pesticides in vegetables } \\
\text { without physical removal of interferences }\end{array}$ & Time-mode augmented & - & [3] [16] \\
\hline & Epoxidized fraction in olive oil & $\begin{array}{l}\text { Cultivar-based classification of olive oils from profile } \\
\text { decomposition of the epoxidized fraction }\end{array}$ & Spectral-mode augmented & NPLS-DA, SIMCA, RF & {$[84]$} \\
\hline & $\begin{array}{l}\text { Anti-tumor drugs in biological } \\
\text { samples }\end{array}$ & $\begin{array}{l}\text { Simultaneous analysis of drugs in biological samples } \\
\text { even when severe time shifts and background } \\
\text { interferences occur }\end{array}$ & Time-mode augmented & ATLD, ATLD-MCR & {$[85]$} \\
\hline & Polyphenols in tea samples & $\begin{array}{l}\text { Dataset deconvoluted for identifying components that } \\
\text { enables modeling for plucking seasons of green tea }\end{array}$ & Time-mode augmented & SVM, PLS-DA & {$[86]$} \\
\hline & $\begin{array}{l}\text { Degradation profile of lowering- } \\
\text { cholesterol drug }\end{array}$ & $\begin{array}{l}\text { Handling the both time elution shifts and similar } \\
\text { spectra with third-order advantage }\end{array}$ & $\begin{array}{l}\text { Kinect time and spectral- } \\
\text { modes unfolded and } \\
\text { retention time augmented }\end{array}$ & & [34] \\
\hline & Preservatives in facial mask & $\begin{array}{l}\text { Fast elution and simple pretreatment for quantitative } \\
\text { analysis of preservatives using multivariate } \\
\text { approaches }\end{array}$ & Time-mode augmented & ATLD & [87] \\
\hline \multirow{3}{*}{ LC-LFD } & PAHs in tea samples & $\begin{array}{l}\text { Strategy to handle non-quadrilinear data for analysis } \\
\text { of PAHs in tea leaves }\end{array}$ & $\begin{array}{l}\text { Dependent time- and } \\
\text { excitation-modes super } \\
\text { augmented }\end{array}$ & & [20] \\
\hline & Organic pollutants in water samples & $\begin{array}{l}\text { Photoinduced fluorescence to detect organic } \\
\text { pollutants in water samples and to quantify with third- } \\
\text { order data treatment }\end{array}$ & Time-mode augmented & & [88] \\
\hline & Quinolones in animal tissues & $\begin{array}{l}\text { Comparison of two multi-way strategies to } \\
\text { simultaneously quantificate antibiotics in animal } \\
\text { tissues with both second- and third-order data }\end{array}$ & Time-mode augmented & U-PLS/RBL, U-PLS/RTL & [21] \\
\hline \multirow{3}{*}{ LC-MS } & $\begin{array}{l}\text { Metabolites of zebrafish exposed to } \\
\text { pesticide }\end{array}$ & $\begin{array}{l}\text { To assess metabolite changes due to exposure to } \\
\text { chlorpyrifos pesticide }\end{array}$ & Time-mode augmented & ASCA & [89] \\
\hline & Untargeted lipids in rice samples & $\begin{array}{l}\text { To assess lipidomic profile of rice under heat and } \\
\text { hydric stresses }\end{array}$ & Time-mode augmented & PCA, ASCA, PLS-DA & [90] \\
\hline & Polyphenols in Chinese propolis & $\begin{array}{l}\text { Quantitative analysis of polyphenols in the presence } \\
\text { of co-elution and interferences in complex matrices }\end{array}$ & Time-mode augmented & ATLD & [91] \\
\hline LCxLC-DAD & $\begin{array}{l}\text { Furanocoumarins in apiaceous } \\
\text { vegetables }\end{array}$ & $\begin{array}{l}\text { To improve quantification of overlapped peaks } \\
\text { by MCR-ALS combining LCxLC resolution to the } \\
\text { detection power of }{ }^{1} \mathrm{D} \text { LC }\end{array}$ & Time-mode augmented & & [92] \\
\hline
\end{tabular}


Table I. Compilation of papers that used MCR-ALS for chromatographic analysis (Continuation)

\begin{tabular}{|c|c|c|c|c|c|}
\hline $\begin{array}{l}\text { Chromatographic } \\
\text { technique }\end{array}$ & Target compounds & Objective & MCR-ALS approach & $\begin{array}{l}\text { Other chemometrics } \\
\text { techniques used }\end{array}$ & Ref. \\
\hline LCxLC-MS & $\begin{array}{l}\text { Untargeted metabolites in rice } \\
\text { samples }\end{array}$ & $\begin{array}{l}\text { To assess metabolite changes of rice as a function of } \\
\text { watering and harvesting time factors }\end{array}$ & Time-mode augmented & ASCA, PLS-DA & [30] \\
\hline & $\begin{array}{l}\text { Untargeted metabolites in Daphnia } \\
\text { magna (crustacean) }\end{array}$ & $\begin{array}{l}\text { To identify metabolites through retention index } \\
\text { and MS database and to evaluate the influence of } \\
\text { environmental factors }\end{array}$ & Time-mode augmented & PCA, ASCA, PLS-DA & [93] \\
\hline & $\begin{array}{l}\text { Terpane, hopane and sterane } \\
\text { (petroleum hydrocarbon) }\end{array}$ & $\begin{array}{l}\text { To investigate the sources of petroleum pollution in a } \\
\text { port region }\end{array}$ & & PCA & {$[94]$} \\
\hline \multicolumn{6}{|l|}{ GC-MS } \\
\hline & Volatile compounds in illicit drugs & $\begin{array}{l}\text { Untargeted analysis of impurities present in illicit } \\
\text { methamphetamine drugs }\end{array}$ & Time-mode augmented & & [95] \\
\hline & $\begin{array}{l}\text { Complex perfume and essential oil } \\
\text { blends }\end{array}$ & $\begin{array}{l}\text { Investigation of characteristics of ylang-ylang oils } \\
\text { used in perfumes, identification of oils used in } \\
\text { blends and quantitative analysis by resolving total } \\
\text { chromatogram average mass spectra }\end{array}$ & Time-mode augmented & PCA, RF & [96] \\
\hline GCXGC-MS & $\begin{array}{l}\text { Untargeted metabolites in lettuce } \\
\text { samples }\end{array}$ & $\begin{array}{l}\text { Investigation of the effects caused in lettuce } \\
\text { morphology in reason of exposure to water } \\
\text { contaminants through metabolite analysis }\end{array}$ & Time-mode augmented & PLS & {$[97]$} \\
\hline CE-DAD & Quinolones in porcine blood & $\begin{array}{l}\text { Quantitative analysis of fluoroquinolones when peaks } \\
\text { are overlapped }\end{array}$ & Time-mode augmented & & [98] \\
\hline $\begin{array}{l}\text { CE-MS + } \\
\text { LC-MS }\end{array}$ & Untargeted metabolites & $\begin{array}{l}\text { Fused data of two chromatographic techniques for } \\
\text { metabolomic analysis of two different conditions for } \\
\text { yeast growth }\end{array}$ & Time-mode augmented & & [25] \\
\hline SFC-DAD & $\begin{array}{l}\text { Carotenoids and coenzime Q10 in } \\
\text { palm oil }\end{array}$ & $\begin{array}{l}\text { Quantitative analysis of bioactive compounds in palm } \\
\text { oil in the presence of interferences via green CO2- } \\
\text { based chromatography }\end{array}$ & Time-mode augmented & & [99] \\
\hline TLC-SERS & $\begin{array}{l}\text { Chemical components of beer } \\
\text { samples }\end{array}$ & $\begin{array}{l}\text { Fingerprinting analysis for classification of Pilsner } \\
\text { beers according to their origins }\end{array}$ & Time-mode augmented & PCA, ICA & {$[100]$} \\
\hline
\end{tabular}




\section{MCR-ALS with augmented elution mode}

Interferents may hinder a univariate quantification even if the extraction step is properly done. Due to non-selectivity of the extraction method, a cleanup step might be required, as for example in the QuEChERS method for pesticide extraction. This procedure could result in lower recovery of the analytes and therefore lower detection. To overcome this issue, Sousa and co-workers [3] proposed a replacement of cleanup step by a chemometric approach with MCR-ALS using HPLC-DAD for separation and detection. The quantification of pesticides was carried out in vegetable samples -tomato, carrot, beet and lettuce. Without a cleanup step, interferents emerged along with analytes.

The data matrix was column-wise augmented (elution mode) for calibration and prediction sample set so that MCR-ALS algorithm could retrieve the pure profiles of each pesticide from a new bilinear matrix even in the presence of co-eluting interference. With this configuration, peak alignment was unnecessary. In order to reduce the rotational ambiguity, the data matrix was divided in four regions containing respectively one, two, one and three analytes based on their elution windows. Also, taking each region individually required less processing efforts and enhanced the selectivity and sensitivity metrics. The spectral profiles retrieved by MCR-ALS for the analytes provided similarities over 0.99 with standards and the area under elution curve retrieved by MCR-ALS provided scores proportional to spiked concentrations, which resulted in reasonable recoveries.

Resolving coeluted peaks where the spectra are different is a classical case where MCR-ALS is used. However, other cases where spectra are identical can be also resolved by MCR-ALS, as discussed below.

\section{MCR-ALS with augmented spectral mode}

Pinto and co-workers [15] reported the separation of five biogenic amines found in fish samples with HPLC-DAD. The amines were derivatized to yield a chromophore for detection mode with dansyl chloride, resulting in very similar spectra. The univariate approach for quantification would require a time -consuming chromatographic run to achieve baseline separation of all compounds. To perform mathematical separation by MCR-ALS the authors [15] performed an isocratic elution with high amount of organic modifier providing a faster run, shorter re-equilibration time and subsequent high-throughput analysis, and better detectability due to narrower peaks. As expected, strong coelution between analytes and interference was observed in a less-than-4 minutes run. Due to spectral similarity, the authors reported the use of MCR-ALS by row-wise augmentation of the data matrix. In order to accomplish that, the elution mode needed to be previously aligned with the icoshift algorithm. After calibration and validation with a test sample set, MCRALS method was applied in spiked fish samples, obtaining recoveries ranging from 88 to $99 \%$. Moreover, this method was applied to the degradation analysis of fish samples over twelve days and one of the analytes (histamine) was found above the recommended limit.

\section{MCR-ALS to solve non-quadrilinearity in third order data}

As mentioned before, MCR-ALS can be useful to extract information from higher order data. Carabajal et al. [20] applied the MCR-ALS to a LC-FLU system with a non-quadrilinearity type 4. They were concerned on accumulated polycyclic aromatic hydrocarbons (PAHs) in tea leaf samples. In an ideal situation, the data matrix obtained from LC-FLU system is a third order/four-way data with samples, elution time and both excitation and emission wavelengths. However, this type of non-quadrilinearity rises from the fact that elution time and excitation modes depend on each other due to the way the data was generated. The authors built a third order LC-FLU data by injecting the same sample changing the excitation wavelength, this system led to a non-quadrilinear type 4 data [20].

In order to solve this problem, the authors proceeded by concatenating both dependent data. As result, the new matrix data contained a three-way array with elution and excitation modes in a so-called super-augmented matrix, while emission mode remained non-augmented. During the constraint input implementation, augmented matrix with time elution and excitation modes were separated to apply unimodality in the former, then reunited. This new matrix is assumed to be bilinear in such a way that 
MCR-ALS can be now applied to retrieve the pure profiles successfully. The developed MCR-ALS method applied to the four PAHs could be used to monitor these contaminants in tea samples. Also, the strategy adopted (LC-FLU-MCR-ALS) was quite faster than the reference method by GC-MS, providing greater analytical frequency.

The third order modeling with non quadrilinear type 4 data was possible to be solved without alignment in this case because the signals were different. When it comes to the same system with rank deficiency, the modeling is even more challenging, but can be solved by a previous alignment or using a multiblock strategy $[15,34]$. To highlight this case, another third order data involves a kinetic profile along elution time and spectra profiles [34].

In a pharmaceutical environment, a description of potential degradation products of the commercialized drug during its shelf life is required by regulatory agencies. However, a usual obstacle is finding the optimal chromatographic conditions for the separation of the active ingredient and its degradation products due to their chemical similarity. On the other hand, because of chemical similarity, the spectral profiles are also very similar, which gives rise to rank deficiency when using MCR-ALS. Pinto and co-workers [34], proposed the use of a third order setup to solve the problem of coelution and spectral similarity in a sample containing atorvastatin and its major degradation products. LC-DAD data was acquired in different degradation times, which provided information for the MCR-ALS modelling. The data was also non quadrilinear type 4, for the same reasons of the previous example.

Using a rapid elution (less than 3 minutes) MCR-ALS was capable of retrieving both chromatographic and spectral profiles, even in the presence of rank deficiency. Besides, since the kinetic profile was present in the data matrix, another profile was retrieved describing the evolution of the concentration of species over the time. In this work the authors used a multiblock strategy, since the kinetic profile gives additional selective information about the system. The major advantage of this strategy is that peak alignment was not necessary to solve rank deficiency, retention time shifts and non quadrilinear type 4 problem simultaneously.

\section{MCR-ALS applied to supercritical fluid chromatography data}

Supercritical fluid chromatography (SFC) is a separation technique that uses dioxide carbon $\left(\mathrm{CO}_{2}\right)$ based mobile phases above $\mathrm{CO}_{2}$ critical pressure. Given the non-polar character of the $\mathrm{CO}_{2}$, an organic modifier such as methanol can be employed to promote elution of polar analytes. In recent years, SFC has regained attention in many fields such as pharmaceutical, natural products and bioanalytical, to mention a few. In addition to SFC usually operates as normal-phase liquid chromatography, the use of an additional organic solvent provides complementary separation compared to the reversed-phase liquid chromatography (RPLC). Recently, solving co-eluting peaks with MCR-ALS has been applied on supercritical fluid chromatography data. Guedes et al. [99] used SFC with $\mathrm{CO}_{2}$-ethanol mobile phase on a C18-stationary phase to separate bioactive compounds from palm oil, namely beta-carotene, lycopene, coenzyme Q10 and lutein. They studied the influence of temperature, pressure, and concentration of ethanol on retention of these compounds by a design of experiments approach. The complex matrix of palm oil required MCR-ALS analysis for the accurate quantification of each compound in the presence of the palm oil interferences.

In another study using SFC, a method for simultaneous analysis of lowering-cholesterol drugs (all commercially available statins and ezetimibe) was developed. After column screening, the stationary phase 1-aminoanthracene (1-AA) was the only column able to slightly separate simvastatin and lovastatin [101]. Separation was attempted by a design of experiments approach to assess the influence of pressure, temperature, and modifier content. However, experimental conditions were unable to obtain acceptable resolutions for this couple of peaks.

In this section, we dealt with these co-eluting peaks on SFC to mathematically separate them by applying MCR-ALS. An obvious advantage was dismissing laborious method development to have a baseline separation of all analytes. The chromatographic conditions were: $10.3 \mathrm{MPa}$ of backpressure, $40^{\circ} \mathrm{C}$ in the 
column oven, flow rate of $1.5 \mathrm{~mL} \mathrm{~min}^{-1}$, mobile phase consisting of $\mathrm{CO}_{2}$ (channel $\mathrm{A}$ ) and methanol:water 95:5 v/v (channel B), gradient ranging from 0 to $30 \%$ of $B$ in 5 minutes. Chromatographic data were acquired in a rate of $20 \mathrm{~Hz}$ and $1.2 \mathrm{~nm}$ of spectral resolution. In this system, there is a region where two overlapped analytes present identical spectra (1 - simvastatin and 2 - lovastatin) and another region where three overlapped analytes present different spectra (3 - ezetimibe, 4 - rosuvastatin and 5 - fluvastatin) (Figure 5A). These overlapped peaks were solved by spectral and retention time augmented matrices, respectively. For the first region (the one with a rank deficiency) a peak alignment with icoshift was first carried out and a spectral augmented (Saug) matrix was used to build the MCR-ALS model (Figure 5B). The second region with different spectral profiles had the elution mode augmented, Caug (Figure 5C).

MCR-ALS algorithm retrieved both spectral and elution profiles and allowed the pseudo-univariate calibration by using area under spectra and chromatographic peak profiles (scores), respectively. This procedure resulted in a linear relationship between MCR-ALS scores and standard concentration (ranging from 10 to $200 \mathrm{mg} \mathrm{L}^{-1}$ ). Validation samples resulted in relative errors of prediction (REP) for actual concentration ranging from $4,39 \%$ (ezetimibe) to $12,73 \%$ (rosuvastatin), meeting criteria for acceptable values according to Horwitz equation, except for rosuvastatin [102].

This work was exploratory in the use of SFC-DAD using a mixture of drug analytes, but it shows that SFC is posed as a potential separation technique along LC and GC for complex matrices. Indeed, SFC faced a rise in its applications in the last decade and the combination with chemometric tools such as MCR-ALS might be of choice for whom desires an orthogonal technique for RPLC, a replacement of toxic solvents used in NPLC and to practice a greener and faster separation due to the $\mathrm{CO}_{2}$-based mobile phases properties. As a conclusion, SFC-MCR-ALS seems to be a good option to solve co-elution problems and interferences when shorter time analysis and lower solvent waste are desired.

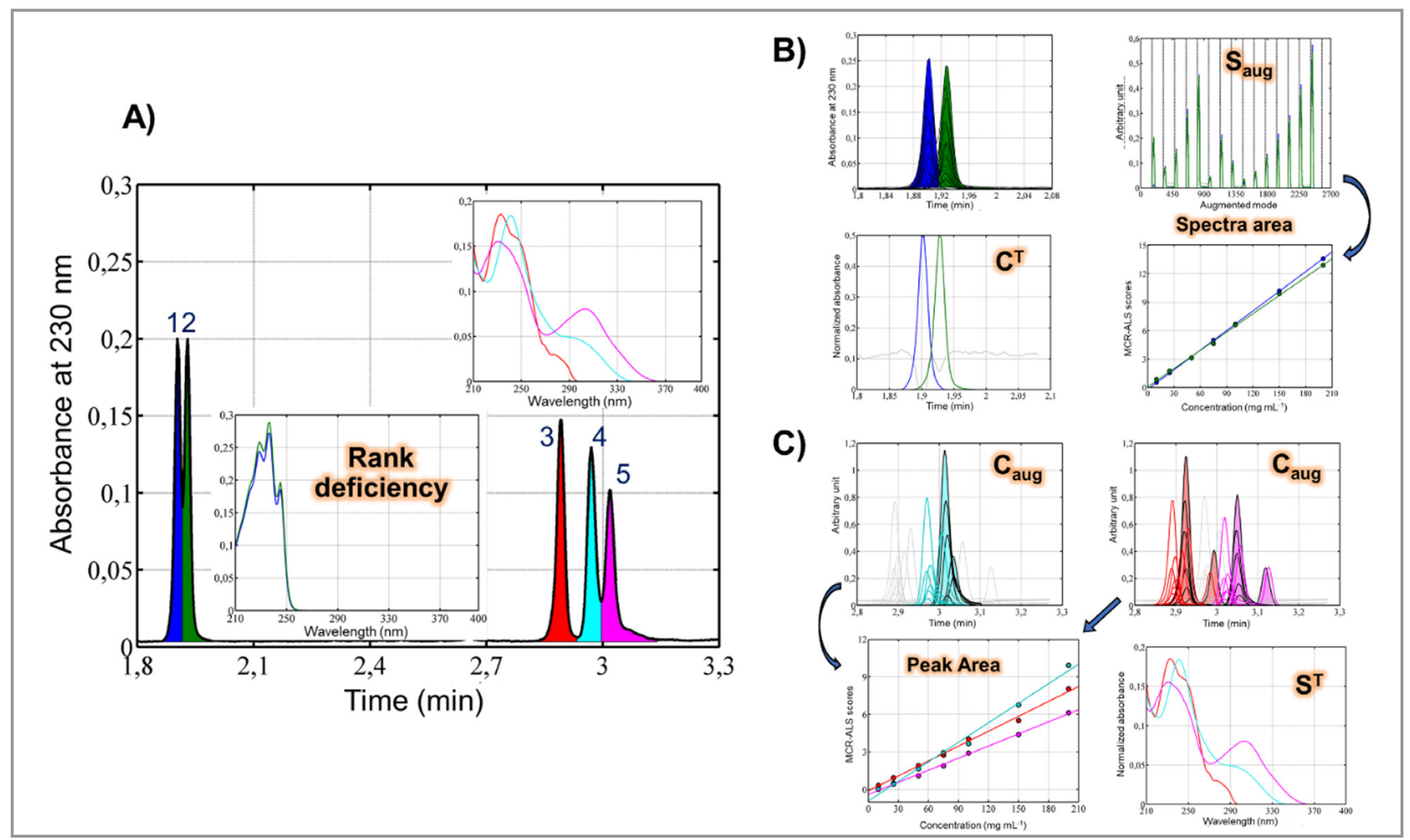

Figure 5. Chromatogram with peaks referring to simvastatin (1), lovastatin (2), ezetimibe (3), rosuvastatin (4) and Fluvastatin (5). Data management was divided in two regions concerning rank deficiency (peaks $1+2$ ) and different spectra $(3+4+5)(A)$. The data of the first region was augmented in the spectral mode $(B)$ and the data from the second region was augmented in the chromatographic mode $(C)$. 


\section{SOFTWARE}

There are many algorithms and toolboxes to implement MCR-ALS for data analysis, some of them are summarized in Table II. The application and the functionality of these algorithms and toolboxes are briefly commented below, for more details the readers are guided to the references. These algorithms and software can be used for many purposes, at Table II highlights only the most important ones.

The first graphical interface for MCR-ALS was developed and implemented in 2005 by Tauler and coauthors [59]. In its latter version, MCR-ALS GUI was implemented in MATLAB environment [43], and used to resolve mixture signals from any kind of analytical data, not only chromatography. Some extensions were included in MCR-ALS basic software, the main ones are MCR Bands [44] used to evaluate the ambiguity of the profiles and ROIMCR software [103] used to select regions of chromatography mass spectrometry data used to metabolomics analysis.

MVC2 GUI [47] and MVC3 GUI [48] are graphical user interfaces implemented in the MATLAB environment for three and four-way data analysis that used the profiles resolved by MCR-ALS to perform a calibration. Both interfaces are unique when it comes to calculating the figures of merit for second and third order calibration. Both interfaces are constantly updated to include new important features. The analyst can also export the recovered profile and see each one for individual samples. The data files must be in txt, commonly exported by most instruments, which eliminates the step of transforming this datafile to MATLAB file.

MCRC software [64] is a graphical interface developed in the MATLAB environment that is based in MCR-ALS GUI. The major advantage is that signal preprocessing such as smooth and baseline correction, other methods to evaluate the chemical and local rank analysis and others initialization algorithms are implemented in a single interface that communicate with MCR-ALS GUI.

Most of the interfaces were initially developed in the MATLAB environment, however, in the past 5 years others MCR-ALS interfaces were developed in free language such as $R[50,104,105]$ and Python 3 $[49,106]$. Differently from other interfaces that can be used for modelling any type of data, these algorithms and interfaces aim at a specific goal. Most of them were developed targeting metabolomics data generated by LC-MS, GC-MS or GCxGC-MS, except from OCTAVVS that was developed to analyze spectroscopy data. Although implementing this algorithm in free language is an important step to increase the visibility and applicability of the algorithm, these interfaces do not use all the constraints that are available in the implemented interfaces for MATLAB. Therefore, these interfaces are better suited for metabolomics analysis than other chromatographic applications.

These interfaces include compressions such as wavelet transform or dividing the data into regions before modelling, which is important in metabolomics. Another strategy that is implemented in MCR-ALS GUI and OCTAVVS is selecting the region of interest (ROI) to search for $\mathrm{m} / \mathrm{z}$ values that are not related to baseline.

The extension of rotational ambiguity can be calculated using MCR-BANDS and/or FACPACK software, both implemented in MATLAB environment, but with different fundamentals to identify the ambiguity $[44,83]$. 
Table II. Free software and toolbox for multivariate curve resolution and rotational ambiguity analysis

\begin{tabular}{|c|c|c|c|c|}
\hline MCR-ALS GUI & MATLAB & Curve resolution & http://www.mcrals.info/ & $\begin{array}{c}{[1,43,} \\
59]\end{array}$ \\
\hline MVC2 GUI & MATLAB & Calibration & http://www.iquir-conicet.gov.ar/descargas/mvc2.rar & {$[47]$} \\
\hline MCRC Software & MATLAB & Curve resolution & http://sharif.edu/ h.parastar/MCRC\%20Software.rar & {$[64]$} \\
\hline RMet & $\mathrm{R}$ & $\begin{array}{l}\text { Metabolomics } \\
\text { analysis }\end{array}$ & https://github.com/SUTChemometricsGroup/RMet & [104] \\
\hline MARS2 & Python 3 & Curve resolution & https://github.com/mapancsu/MARS2 & {$[106]$} \\
\hline OCTAVVS & Python 3 & Curve resolution & https://pypi.org/project/octavvs/ & {$[49]$} \\
\hline MCR Bands & MATLAB & Ambiguity analysis & http://www.mcrals.info/ & {$[44]$} \\
\hline FACPACK & MATLAB & Ambiguity analysis & $\begin{array}{l}\text { http://www.math.uni-rostock.de/facpack/Downloads. } \\
\text { html }\end{array}$ & [83] \\
\hline
\end{tabular}

\section{OUTLOOK AND CONCLUSIONS}

In the present review, the fundamentals and important aspects of MCR-ALS such as constraints, ambiguities and rank deficiency issues were presented for the analysis of chromatographic data. The importance of multivariate mathematical separation was discussed, especially for the analysis of complex samples. Since modern analytical chemistry provides different possibilities of acquiring information about the samples under study, the data organization was also addressed in this review. Recent advances and significant applications were described in an extensive revision of the papers published up to 2020.

It is interesting to note how MCR-ALS evolved over the past five decades. In the last decade much effort was made in two fields: (1) develop strategies to analyze metabolomic data such as the ROI and multiblock analysis, and (2) evaluate the extension of rotational ambiguity where MCR-BANDS and AFS tools can be highlighted. It is expected that the use of MCR-ALS will continue evolving in the near future and become part of the commercial software for chromatography.

\section{Conflicts of interest}

All the authors declare no conflict of interest.

\section{Acknowledgements}

Licarion Pinto thank the Brazilian Funding Agencies, FACEPE 14/2019 INOVA IAM process numberAPQ0437-1.06/19 and the "Instituto Nacional de Ciência e Tecnologia de Bioanalítica (INCT- Bioanalítica)". Igor Miranda Santana is grateful to CNPq for the PhD scholarship (131217/2017-8). Marcia Cristina Breitkreitz thanks FAPESP (process number 2016/05636-9) and INCT-Bioanalítica. 


\section{REFERENCES}

1. de Juan, A.; Tauler, R. Anal. Chim. Acta., 2021, 1145, pp 59-78 (https://doi.org/10.1016/j. aca.2020.10.051).

2. Amigo, J. M.; Skov, T.; Bro, R. Chem. Rev., 2010, 110 (8), pp 4582-4605 (https://doi.org/10.1021/ cr900394n).

3. Sousa, E. S.; Pinto, L.; de Araujo, M. C. U. Microchem. J., 2017, 134, pp 131-139 (https://doi. org/10.1016/j.microc.2017.05.017).

4. Lawton, W. H.; Sylvestre, E. A. Technometrics, 1971, 13 (3), pp 617-633 (https://doi. org/10.2307/1267173).

5. Osten, D. W.; Kowalski, B. R. Anal. Chem., 1984, 56 (6), pp 991-995 (https://doi.org/10.1021/ ac00270a029).

6. Escandar, G. M.; Goiocoechea, H. C.; de la Peña. A. M.; Olivieri, A. C. Anal. Chim. Acta., 2014, 806, pp 8-26 (https://doi.org/10.1016/j.aca.2013.11.009).

7. Mounier, S.; Nicolodelli, G.; Redon, R.; Milori, D. M. B. P. Spectrochim. Acta, Part A, 2017, 177, pp 79-85 (https://doi.org/10.1016/j.saa.2017.01.017).

8. Santos, M. C. D.; Azcarate, S. M.; Lima, K. M. G.; Goicoechea, H. C. Microchem. J., 2020, 155, pp 104783 (https://doi.org/10.1016/j.microc.2020.104783).

9. Yin, X.-L.; Gu, H.-W.; Liu, X.-L.; Zhang, S.-H.; Wu, H.-L. Spectrochim. Acta, Part A, 2018, 192, pp 437-445 (https://doi.org/10.1016/j.saa.2017.11.047).

10. Silva, A. C.; Pinto, L.; Gomes, A. A.; de Araujo, M. C. U. J. Braz. Chem. Soc., 2019, 30 (2), pp 398405 (https://doi.org/10.21577/0103-5053.20180189).

11. Fernández, L. P.; Brasca, R.; Goicoechea, H.; Culzoni, M. J. Microchem. J., 2020, 159, pp 105315 (https://doi.org/10.1016/j.microc.2020.105315).

12. Girón, A. J.; Durán-Merás, I.; Espinosa-Mansilla, A.; de la Peña, A. M.; Cañada, F. C.; Olivieri, A. C. Anal. Chim. Acta, 2008, 622 (1-2), pp 94-103 (https://doi.org/10.1016/j.aca.2008.05.079).

13. Carabajal, M. D.; Arancibia, J. A.; Escandar, G. M. Talanta, 2017, 165, pp 52-63 (https://doi. org/10.1016/j.talanta.2016.12.030).

14. Fernández, C.; Callao, M. P.; Larrechi, M. S. Talanta, 2013, 117, pp 75-80 (https://doi.org/10.1016/j. talanta.2013.08.004).

15. Pinto, L.; Diaz Nieto, C. H.; Zon, M. A.; Fernández, H.; de Araujo, M. C. U. Anal. Chim. Acta, 2016, 902, pp 59-69 (https://doi.org/10.1016/j.aca.2015.10.043).

16. Sousa, E. S.; Schneider, M. P.; Pinto, L.; de Araujo, M. C. U.; Gomes, A. A. Microchem. J., 2020 152, pp 104301 (https://doi.org/10.1016/j.microc.2019.104301).

17. Escandar, G. M.; Olivieri, A. C. J. Chromatogr. A, 2019, 1587, pp 2-13 (https://doi.org/10.1016/j. chroma.2019.01.012).

18. Moreira, E. D. T.; Pinto, L.; Gomes, A. A.; Goicoechea, H. C.; de Araujo, M. C. U. J. Braz. Chem. Soc., 2015, 26 (8), pp 1573-1582 (https://doi.org/10.5935/0103-5053.20150125).

19. Montemurro, M.; Pinto, L.; Véras, G.; Gomes, A. A.; Culzoni, M. J.; de Araujo, M. C. U.; Goicoechea, H. C. Talanta, 2016, 154, pp 208-218 (https://doi.org/10.1016/j.talanta.2016.03.078).

20. Carabajal, M. D.; Arancibia, J. A.; Escandar, G. M. Talanta, 2018, 189, pp 509-516 (https://doi. org/10.1016/j.talanta.2018.07.017).

21. Anzardi, M. B.; Arancibia, J. A.; Olivieri, A. C. Chemom. Intell. Lab. Syst., 2020, 199, 103972 (https:// doi.org/10.1016/j.chemolab.2020.103972).

22. Vidal, R. B. P.; Ibañez, G. A.; Escandar, G. M. Anal. Chem., 2017, 89 (5), pp 3029-3035 (https://doi. org/10.1021/acs.analchem.6b04720).

23. Montemurro, M.; Siano, G. G.; Alcaráz, M. R.; Goicoechea, H. C. Trends Anal. Chem., 2017, 93, pp 119-133 (https://doi.org/10.1016/j.trac.2017.05.011).

24. Gorrochategui, E.; Jaumot, J.; Lacorte, S.; Tauler, R. Trends Anal. Chem., 2016, 82, pp 425-442 (https://doi.org/10.1016/j.trac.2016.07.004). 
25. Ortiz-Villanueva, E.; Benavente, F.; Piña, B.; Sanz-Nebot, V.; Tauler, R.; Jaumot, J. Anal. Chim. Acta, 2017, 978, pp 10-23 (https://doi.org/10.1016/j.aca.2017.04.049).

26. Bos, T. S.; Knol, W. C.; Molenaar, S. R. A.; Niezen, L. E.; Schoenmakers, P. J.; Somsen, G. W.; Pirok, B. W. J. J. Sep. Sci., 2020, 43 (9-10), pp 1678-1727 (https://doi.org/10.1002/jssc.202000011).

27. de Godoy, L. A. F.; Hantao, L. W.; Pedroso, M. P.; Poppi, R. J.; Augusto, F. Anal. Chim. Acta, 2011, 699, pp 120-125 (https://doi.org/10.1016/j.aca.2011.05.003).

28. Bahaghighat, H. D.; Freye, C. E.; Gough, D. V.; Synovec, R. E. J. Chromatogr. A, 2019, 1583, pp 117-123 (https://doi.org/10.1016/j.chroma.2018.11.027).

29. Parastar, H.; Radović, J. R.; Jalali-Heravi, M.; Diez, S.; Bayona, J. M.; Tauler, R. Anal. Chem., 2011, 83 (24), pp 9289-9297 (https://doi.org/10.1021/ac201799r).

30. Navarro-Reig, M.; Jaumot, J.; Baglai, A.; Vivó-Truyols, G.; Schoenmakers, P. J.; Tauler, R. Anal. Chem., 2017, 89 (14), pp 7675-7683 (https://doi.org/10.1021/acs.analchem.7b01648).

31. Pérez-Cova, M.; Tauler, R.; Jaumot, J. Chemom. Intell. Lab. Syst., 2020, 201, 104009 (https://doi. org/10.1016/j.chemolab.2020.104009).

32. Prebihalo, S. E.; Berrier, K. L.; Freye, C. E.; Bahaghighat, H. D.; Moore, N. R.; Pinkerton, D. K.; Synovec, R. E. Anal. Chem., 2018, 90 (1), pp 505-532 (https://doi.org/10.1021/acs.analchem.7b04226).

33. Porter, S. E. G.; Stoll, D. R.; Rutan, S. C.; Carr, P. W.; Cohen, J. D. Anal. Chem., 2006, 78 (15), pp 5559-5569 (https://doi.org/10.1021/ac0606195).

34. Pinto, L.; Jardim, I. C. S. F.; Rutledge, D. N.; Breitkreitz, M. C. Anal. Chim. Acta, 2020, 1133, pp 7787 (https://doi.org/10.1016/j.aca.2020.08.008).

35. Dwight, S.; Rutan, R.; Venkatramani, S. C.; Cook, C. J.; Daniel, W. LCGC North Am., 2018, 36 (4), pp 248-255. Available from: https://www.chromatographyonline.com/view/peak-purity-liquidchromatography-part-ii-potential-curve-resolution-techniques [Acessed 01 March 2020].

36. Montemurro, M.; Siano, G. G.; Alcaráz, M. R.; Goicoechea, H. C. Trends Anal. Chem., 2017, 93, pp 119-133 (https://doi.org/10.1016/j.trac.2017.05.011).

37. Olivieri, A. C. Anal. Chem., 2008, 80 (15), pp 5713-5720 (https://doi.org/10.1021/ac800692c).

38. Olivieri, A. C. Chem. Rev., 2014, 114 (10), pp 5358-5378 (https://doi.org/10.1021/cr400455s).

39. Grisales, J. O.; Arancibia, J. A.; Castells, C. B.; Olivieri, A. C. J. Chromatogr. B: Anal. Technol. Biomed. Life Sci., 2012, 910, pp 78-83 (https://doi.org/10.1016/j.jchromb.2012.04.018).

40. Wu, H.-L.; Wang, T.; Yu, R.-Q. Trends Anal. Chem., 2020, 130, 115954 (https://doi.org/10.1016/j. trac.2020.115954).

41. Arancibia, J. A.; Damiani, P. C.; Escandar, G. M.; Ibañez, G. A.; Olivieri, A. C. J. Chromatogr. B: Anal. Technol. Biomed. Life Sci., 2012, 910, pp 22-30 (https://doi.org/10.1016/j.jchromb.2012.02.004).

42. Tauler, R.; Barceló, D. Trends Anal. Chem., 1993, 12 (8), pp 319-327 (https://doi.org/10.1016/01659936(93)88015-W).

43. Jaumot, J.; de Juan, A.; Tauler, R. Chemom. Intell. Lab. Syst., 2015, 140, pp 1-12 (https://doi. org/10.1016/j.chemolab.2014.10.003).

44. Jaumot, J.; Tauler, R. Chemom. Intell. Lab. Syst., 2010, 103 (2), pp 96-107 (https://doi.org/10.1016/j. chemolab.2010.05.020).

45. Ruckebusch, C.; Blanchet, L. Anal. Chim. Acta, 2013, 765, pp 28-36 (https://doi.org/10.1016/j. aca.2012.12.028).

46. Vidal, R. B. P.; Olivieri, A. C. Anal. Chim. Acta, 2019, 1078, pp 8-15 (https://doi.org/10.1016/j. aca.2019.06.038).

47. Olivieri, A. C.; Wu, H.-L.; Yu, R.-Q. Chemom. Intell. Lab. Syst., 2009, 96 (2), pp 246-251 (https://doi. org/10.1016/j.chemolab.2009.02.005).

48. Olivieri, A. C.; Wu, H.-L.; Yu, R.-Q. Chemom. Intell. Lab. Syst., 2012, 116, pp 9-16 (https://doi. org/10.1016/j.chemolab.2012.03.018).

49. Troein, C.; Siregar, S.; De Beeck, M. O.; Peterson, C.; Tunlid, A.; Persson, P. Methods Protocol., 2020, 3 (2), 34 (https://doi.org/10.3390/mps3020034). 
50. Wehrens, R.; Carvalho, E.; Fraser, P. D. Metabolomics, 2015, 11, pp 143-154 (https://doi.org/10.1007/ s11306-014-0683-5).

51. Shen, H.; Stordrange, L.; Manne, R.; Kvalheim, O. M.; Liang, Y. Chemom. Intell. Lab. Syst., 2000, 51 (1), pp 37-47 (https://doi.org/10.1016/S0169-7439(99)00066-0).

52. Shen, H.; Liang, Y.; Kvalheim, O. M.; Manne, R. Chemom. Intell. Lab. Syst., 2000, 51 (1), pp 49-59 (https://doi.org/10.1016/S0169-7439(00)00054-X).

53. Culzoni, M. J.; de Llanos, A. M.; De Zan, M. M.; Espinosa-Mansilla, A.; Cañada-Cañada, F.; de la Peña, A. M.; Goicoechea, H. C. Talanta, 2011, 85 (5), pp 2368-2374 (https://doi.org/10.1016/j. talanta.2011.07.086).

54. Culzoni, M. J.; Goicoechea, H. C.; Ibañez, G. A.; Lozano, V. A.; Marsili, N. R.; Olivieri, A. C.; Pagani, A. P. Anal. Chim. Acta, 2008, 614 (1), pp 46-57 (https://doi.org/10.1016/j.aca.2008.03.013).

55. Parastar, H.; Akvan, N. Anal. Chim. Acta, 2014, 816, pp 18-27 (https://doi.org/10.1016/j. aca.2014.01.051).

56. Pinto, L.; Stechi, F.; Breitkreitz, M. C. Microchem. J., 2019, 146, pp 202-209 (https://doi.org/10.1016/j. microc.2019.01.014).

57. Parastar, H.; Shaye, H. RSC Adv., 2015, 5 (86), pp 70017-70024 (https://doi.org/10.1039/ C5RA10658C).

58. Olivieri, A. C.; Escandar, G. M.; Goicoechea, H. C.; de la Peña, A. M. Fundamentals and Analytical Applications of Multiway Calibration. Elsevier, 2015.

59. Jaumot, J.; Gargallo, R.; de Juan, A.; Tauler, R. Chemom. Intell. Lab. Syst., 2005, 76 (1), pp 101-110 (https://doi.org/10.1016/j.chemolab.2004.12.007).

60. Keller, H. R.; Massart, D. L. Chemom. Intell. Lab. Syst., 1991, 12 (3), pp 209-224 (https://doi. org/10.1016/0169-7439(92)80002-L).

61. Maeder, M. Anal. Chem., 1987, 59 (3), pp 527-530 (https://doi.org/10.1021/ac00130a035).

62. Sánchez, F. C.; van den Bogaert, B.; Rutan, S. C.; Massart, D. L. Chemom. Intell. Lab. Syst., 1996, 34 (2), pp 139-171 (https://doi.org/10.1016/0169-7439(96)00020-2).

63. Windig, W.; Guilment, J. Anal. Chem., 1991, 63 (14), pp 1425-1432 (https://doi.org/10.1021/ ac00014a016).

64. Jalali-Heravi, M.; Parastar, H.; Kamalzadeh, M.; Tauler, R.; Jaumot, J. Chemom. Intell. Lab. Syst., 2010, 104 (2), pp 155-171 (https://doi.org/10.1016/j.chemolab.2010.08.002).

65. Rodríguez-Cuesta, M. J.; Bosqué, R.; Rius, F. X. Anal. Chim. Acta, 2003, 476 (1), pp 111-122 (https:// doi.org/10.1016/S0003-2670(02)01360-0).

66. Navea, S.; Tauler, R.; de Juan, A. Anal. Chem., 2006, 78 (14), pp 4768-4778 (https://doi.org/10.1021/ ac052257r).

67. Kuligowski, J.; Quintás, G.; Tauler, R.; Lendl, B.; de la Guardia, M. Anal. Chem., 2011, 83 (12), pp 4855-4862 (https://doi.org/10.1021/ac2004407).

68. Malik, A.; Tauler, R. Chemom. Intell. Lab. Syst., 2014, 135, pp 223-234 (https://doi.org/10.1016/j. chemolab.2014.04.002).

69. Antunes, M. C.; Simão, J. E. J.; Duarte, A. C.; Tauler, R. Analyst, 2002, 127 (6), pp 809-817 (https:// doi.org/10.1039/b200243b).

70. Mallat, E.; Barceló, D.; Tauler, R. Chromatographia, 1997, 46, pp 342-350 (https://doi.org/10.1007/ BF02490871).

71. de Juan, A.; Maeder, M.; Martínez, M.; Tauler, R. Chemom. Intell. Lab. Syst., 2000, 54 (2), pp 123141 (https://doi.org/10.1016/S0169-7439(00)00112-X).

72. Van Benthem, M. H.; Keenan, M. R.; Haaland, D. M. J. Chemom., 2002, 16 (12), pp 613-622 (https:// doi.org/10.1002/cem.761).

73. Schröder, H.; Sawall, M.; Kubis, C.; Jürß, A.; Selent, D.; Brächer, A.; Börner, A.; Franke, R.; Neymeyr, K. Chemom. Intell. Lab. Syst., 2017, 163, pp 55-63 (https://doi.org/10.1016/j.chemolab.2017.02.002).

74. Zhang, X.; Zhang, Z.; Tauler, R. Talanta, 2019, 202, pp 554-564 (https://doi.org/10.1016/j. talanta.2019.05.002). 
75. Dadashi, M.; Abdollahi, H.; Tauler, R. Chemom. Intell. Lab. Syst., 2017, 162, pp 203-213 (https://doi. org/10.1016/j.chemolab.2017.01.009).

76. Zhang, X.; Tauler, R. Chemom. Intell. Lab. Syst., 2015, 147, pp 47-57 (https://doi.org/10.1016/j. chemolab.2015.08.005).

77. Tauler, R. Anal. Chim. Acta, 2007, 595 (1-2), pp 289-298 (https://doi.org/10.1016/j.aca.2006.12.043).

78. Vosough, M.; Mason, C.; Tauler, R.; Jalali-Heravi, M.; Maeder, M. J. Chemom., 2006, 20 (6-7), pp 302-310 (https://doi.org/10.1002/cem.1022).

79. Tauler, R. J. Chemom., 2001, 15 (8), pp 627-646 (https://doi.org/10.1002/cem.654).

80. Tauler, R.; Smilde, A.; Kowalski, B. J. Chemom., 1995, 9 (1), pp 31-58 (https://doi.org/10.1002/ cem.1180090105).

81. Sawall, M.; Neymeyr, K. Anal. Chim. Acta, 2017, 960, pp 40-52 (https://doi.org/10.1016/j. aca.2016.11.069).

82. Lakeh, M. A.; Abdollahi, H.; Gemperline, P. J. Anal. Chim. Acta, 2020, 1105, pp 64-73 (https://doi. org/10.1016/j.aca.2020.01.022).

83. Sawall, M.; Neymeyr, K. Anal. Chim. Acta, 2014, 828, pp 17-26 (https://doi.org/10.1016/j. aca.2014.04.026).

84. Jiménez-Carvelo, A. M.; Cruz, C. M.; Olivieri, A. C.; González-Casado, A.; Cuadros-Rodríguez, L. Talanta, 2019, 195, pp 69-76 (https://doi.org/10.1016/j.talanta.2018.11.033).

85. Chang, Y.; Wu, H.; Fang, H.; Wang, T.; Ouyang, Y.; Sun, X.; Tong, G.; Ding, Y.; Yu, R. Talanta, 2021, 224, 121798 (https://doi.org/10.1016/j.talanta.2020.121798).

86. Peng, T.; Yin, X.; Gu, H.; Sun, W.; Ding, B.; Hu, X.; Ma, L.; Wei, S.; Liu, Z.; Ye, S. Food Chem., 2021, 347, 128959 (https://doi.org/10.1016/j.foodchem.2020.128959).

87. Yin, X.; Gu, H.; Jalalvand, A. R.; Liu, Y.; Chen, Y.; Peng, T. J. Chromatogr. A, 2018, 1573, pp 18-27 (https://doi.org/10.1016/j.chroma.2018.09.019).

88. Vidal, R. B. P.; Olivieri, A. C.; Ibañez, G. A.; Escandar, G. M. ACS Omega, 2018, 3 (11), pp 1577115779 (https://doi.org/10.1021/acsomega.8b02439).

89. Gómez-Canela, C.; Prats, E.; Piña, B.; Tauler, R. Environ. Pollut., 2017, 220, pp 1231-1243 (https:// doi.org/10.1016/j.envpol.2016.11.010).

90. Navarro-Reig, M.; Tauler, R.; Iriondo-Frias, G.; Jaumot, J. J. Chromatogr. B: Anal. Technol. Biomed. Life Sci., 2019, 1104, pp 148-156 (https://doi.org/10.1016/j.jchromb.2018.11.018).

91. Long, W.; Wu, H.; Wang, T.; Dong, M.; Yu, R. Microchem. J., 2020, 157, 105003 (https://doi. org/10.1016/j.microc.2020.105003).

92. Cook, D. W.; Burnham, M. L.; Harmes, D. C.; Stoll, D. R.; Rutan, S. C. Anal. Chim. Acta, 2017, 961, pp 49 - 58 (https://doi.org/10.1016/j.aca.2017.01.047).

93. Garreta-Lara, E.; Campos, B.; Barata, C.; Lacorte, S.; Tauler, R. Sci. Total Environ., 2018, 610-611, pp 602-612 (https://doi.org/10.1016/j.scitotenv.2017.05.190).

94. Azimi, A.; Bahktiari, A. R.; Tauler, R. Environ. Pollut., 2018, 243, pp 374-382 (https://doi.org/10.1016/j. envpol.2018.08.073).

95. Shekari, N.; Vosough, M.; Heidar, K. T. J. Sep. Sci., 2017, 40 (6), pp 1318-1326 (https://doi. org/10.1002/jssc.201601313).

96. Lebanov, L.; Tedone, L.; Ghiasvand, A.; Paull, B. Talanta, 2020, 219, 121208 (https://doi.org/10.1016/j. talanta.2020.121208).

97. Hurtado, C.; Parastar, H.; Matamoros, V.; Piña, B.; Tauler, R.; Bayona, J. M. Sci. Rep., 2017, 7, 6546 (https://doi.org/10.1038/s41598-017-06773-0).

98. Teglia, C. M.; Cámara, M. S.; Vera-Candioti, L. Electrophoresis, 2017, 38, pp 1122-1129 (https://doi. org/10.1002/elps.201600475).

99. Guedes, L. S.; Santana, C. C.; Rutledge, D. N.; Pinto, L.; Jardim, I. C. S. F.; de Melo, L. V.; Beppu, M. M.; Breitkreitz, M. C. Can. J. Chem. Eng., 2021, pp 1-16 (https://doi.org/10.1002/cjce.23969). 
100. Soares, F. L. F.; Ardila, J. A.; Carneiro, R. L. J. Raman Spectrosc., 2017, 48, pp 943-950 (https://doi. org/10.1002/jrs.5168).

101. Santana, I. M.; Jardim, I. C. S. F.; Breitkreitz, M. C. J. Sep. Sci., 2020, 43 (22), pp 4234-4242 (https:// doi.org/10.1002/jssc.202000702).

102. US Food and Drug Administration. Guidelines for the Validation of Chemical Methods in Food, Feed, Cosmetics, and Veterinary Products (3rd Ed.). Silver Spring, MD, USA: FDA, 2019.

103. Gorrochategui, E.; Jaumot, J.; Tauler, R. BMC Bioinf., 2019, 20, Article number 256 (https://doi. org/10.1186/s12859-019-2848-8).

104. Moayedpour, S.; Parastar, H. Chemom. Intell. Lab. Syst., 2019, 194, 103866 (https://doi.org/10.1016/j. chemolab.2019.103866).

105. Smirnov, A.; Qiu, Y.; Jia, W.; Walker, D. I.; Jones, D. P.; Du, X. Anal. Chem., 2019, 91 (14), pp 90699077 (https://doi.org/10.1021/acs.analchem.9b01424).

106. Ma, P.; Li, M.; Lu, H.; Zhang, Z. Chemom. Intell. Lab. Syst., 2019, 191, pp 12-20 (https://doi. org/10.1016/j.chemolab.2019.05.010). 